Ссылка: Бурденко Е.В. Качество образовательных услуг в инновачионной экономике// Федеральный бюджет на 2012-2014 годы: инструмент модернизации российской экономики (наука и образование): (по материалам круглого стола), 7 октября 2011 г. - М.: Изд-во РЭУ им. Г.В. Плеханова, 2011. с.90-95.

http://elibrary.ru/item.asp?id=25429327

\title{
КАЧЕСТВО ОБРАЗОВАТЕЛЬНЫХ УСЛУГ В ИННОВАЦИОННОЙ ЭКОНОМИКЕ
}

Бурденко Елена Викторовна - почетный работник высшего профессионального образования, кандидат экономических наук, доцент кафедры политической экономии Российского экономического университета им. Г.В. Плеханова,

ResearcherID: E-3369-2014

orcid.org/0000-0001-5073-5062

burdenko-ev@yandex.ru

Аннотация

Статье рассмотрены стандарты качества, регламентирующие представления образовательных услуг высшего образования как в России, так и в мире.

Ключевые слова: образовательная услуга, менеджмент качества, стандарт качества, высшее образование.

\section{THE QUALITY OF EDUCATIONAL SERVICES IN THE INNOVATION ECONOMY}

Burdenko, Elena V. - honorary worker of higher professional education, $\mathrm{PhD}$, Assistant Professor of the Department for Political Economy of the Plekhanov Russian University of Economics,

ResearcherID: E-3369-2014

orcid.org/0000-0001-5073-5062

burdenko-ev@yandex.ru

Abstract

The article the quality standards governing the presentation of educational services of higher education in Russia and in the world.

Keywords: educational services, quality management, quality standard, higher education. 


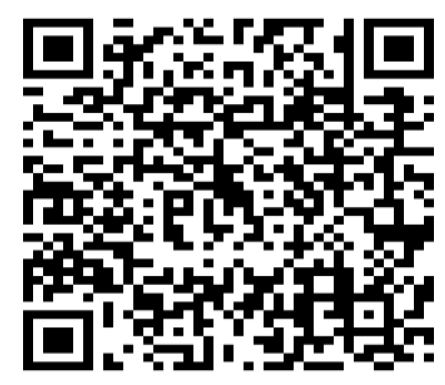

К.э.н., доц. Бурденко Е.В.

\section{КАЧЕСТВО ОБРАЗОВАТЕЛЬНЫХ УСЛУГ В ИННОВАЦИОННОЙ ЭКОНОМИКЕ}

В современных условиях на российское высшее образовательное учреждение оказывают влияния такие процессы как присоединение к болонской декларации, так и развитие, внедрение инновационных форм и методов преподавания. Все это предполагает реформирование системы образования и внедрение в вузах такой системы, как «Система менеджмента качества образовательной деятельности вуза».

В России создана государственная система аттестации и контроля качества на уровне государства (департамент аттестации и контроля качества образования при Министерстве образования и науки РФ), а также сформированы подобные структуры во всех субъектах Российской Федерации и в каждом вузе обязательно должен быть создан отдел качества образования. Однако следует отметить, что данные структуры не ограничиваются только функцией контроля, необходимо постоянно обеспечивать и управлять качеством образования в процессе предоставления образовательных услуг. Эти процессы не дублируют, а взаимно дополняют друг друга. Создание системы управления качеством в вузе дает возможность им ориентировать свою деятельность на удовлетворение требований потребителей образовательных услуг, активизировать деятельность в области обеспечения качества, 
упорядочить документооборот, создать систему ответственности за качество, а также гарантировать внешнему окружению качество образования в соответствие с принятыми нормами и стандартами.

Остановимся на моделях управления качеством образования в высшей школе, к которым можно отнести следующие:

1. Модель системы менеджмента качества, соответствующая международному стандарту ИСО 9001:2000. В России международные стандарты ИСО 9000 приняты в качестве национальных стандартов ГОСТ Р в 1988 году. В 2001 г. статус ГОСТ Р приобрела и новая версия международных стандартов ИСО серии 9000:2000.

2. Модель Европейского фонда по менеджменту качества (EFQM) ${ }^{1}$.

3. Модели национальных и региональных премий по качеству и их модификаций для высшего образования.

4. Модель управления качеством в вузах на основе принципов $\mathrm{TQM}^{2}$. Рассмотрим эти модели более подробно.

1. Модель системы менеджмента качества, соответствующая международному стандарту ISO 9001:2000. Международные стандарты серии ISO были разработаны и утверждены в 1987 году международной организацией по стандартизации ИСО. В 1994 и 2000 годах была осуществлена работа по их пересмотру с учета накопленного опыта применения. В настоящее время более 160 стран признали МС ИСО в качестве национальных или гармонизировали их в соответствии с национальными стандартами. В мире более 500 тыс. компаний добровольно сертифицировали свои системы качества в соответствии с МС ИСО серии 9000. В последние годы в России

\footnotetext{
${ }^{1}$ European Foundation for Quality Management (EFQM) Европейский Фонд менеджмента качества - некоммерческая организация, созданная в 1987 году четырнадцатью ведущими европейскими компаниями (Bosh, BT, Bull, Ciba-Geigy, Dassault, Electrolux, Fiat, KLM, Nestle, Olivetti, Philips, Renault, Sulzer, Volkswagen) при поддержке Комиссии EC.

${ }^{2} \mathrm{TQM}$ - Total Quality Management.
} 
значительно вырос интерес предприятий к внедрению и сертификации систем менеджмента качества и использованию в этой связи международные стандарты ИСО серии 9000.

Главным преимуществом МС ИСО серии 9000:2000 является то, что требования к системам общего руководства качеством ориентированы не только на обеспечение соответствия качества продукции стандартам, но и включают потребность организации в демонстрации её возможностей добиться удовлетворения потребителей за счет улучшения качества выпускаемой продукции и производимых услуг. Исключительно важным для вузов является ориентация МС ИСО серии 9000:2000 на процессный подход, то есть вся деятельность вуза может быть представлена в виде процессов.

В 2004 году разработан международный стандарт ИСО/IWA «Системы менеджмента качества. Руководящие указания по применению ИСО 9001:2000 в образовании». В РФ в 2008 г. принят стандарт ГОСТ Р ИСО/IWA 2 «Системы менеджмента качества. Руководящие указания по применению ИСО 9001:2000 в образовании», то есть полностью идентичный международному.

Формирование модели управления качеством в вузе в соответствии с международными стандартами ИСО серии 9000:2000 позволяет реализовать основные принципы TQM, среди которых:

- ориентация всей деятельности вуза на потребителей, от удовлетворения которых зависит конкурентоспособность вуза;

- $\quad$ непрерывное улучшение процессов образовательной и научноисследовательской работы вуза;

- $\quad$ обеспечение участия руководства, сотрудников и профессорскопреподавательского состава в решении проблем качества;

- $\quad$ концентрация усилий в сфере качества, направленных на развитие человеческих взаимоотношений; 
- ориентация на предупреждение несоответствий стандартам;

- $\quad$ трактовка обеспечения качества как непрерывного процесса, когда качество конечного объекта является следствием достижения соответствующего качества на всех предыдущих этапах этого процесса.

2. Модель Европейского фонда по менеджменту качества (EFQM) и её модификации для высшего образования. Европейским фондом менеджмента качества (EFQM), Комиссией ЕС и Европейской организацией по качеству (ЕОК) в 1991 году учреждена европейская премия по качеству. Целью Европейской премии по качеству является стимулирование и мотивация деятельности европейских компаний в области повышения качества товаров и услуг. Оценка участников конкурса на соискание этой премии проводится по 1000-бальной системе по 9-ти критериям, которые разделены на две группы: «Возможности» (500 баллов) и «Результаты» (500 баллов). По каждому критерию Европейской премии качества установлены рекомендуемые и дополнительные оценочные показатели [2].

Модификацией Европейской премии по качеству является Европейская система улучшения качества (European Quality Improvement System), которая была учреждена Европейским фондом менеджмента образования (EFME). Эта модель основана на оценке десяти отдельных направлений. В основе модели лежит использование самооценки организации, подготовка на ее основе отчета конкурсанта и оценка его внешними экспертами. В рамках конкурса на соискание премии в области качества самооценка представляет собой процесс внутренний оценки качества работы организации, проводимой самим учреждением в соответствии с установленными критериями. Проведение самооценки дает организациям ряд преимуществ: 
1. использование при оценке деятельности и результатов единого комплекса критериев;

2. систематический подход к совершенствованию деятельности;

3. получение объективных оценок, основанных на фактах, не на субъективном восприятии отдельных работников или руководителей;

4. согласованное понимание всеми подразделениями и каждым работником того, что в данной ситуации должна делать организация в целом, исходя из концептуального подхода;

5. обучение персонала принципам всеобщего управления качеством;

6. внедрение различных инициатив и передовых методов управления качеством в деятельность организации;

7. выявление и анализ процессов, в которые можно ввести улучшения;

8. определение изменений, произошедших с момента проведения прошлой самооценки;

9. возможность распространения передового опыта лучших подразделений как данного предприятия, так и других;

10. возможность признания и стимулирования достижений лучших подразделений и работников и т.д.

Европейская модель премии в области качества лежит в основе многих национальных премий в области качества.

В конце 2001 г. ЕFQМ принял схему признания соответствия организаций Модели Совершенства, установив несколько уровней совершенства.

Верхний уровень - признание в рамках конкурса на Европейскую награду за Совершенство (ЕЕА).

На этом уровне выделяются:

^ Победители конкурса - обладатели EEA (Award Winners); 
^ Призеры (Prize Winners);

А Финалисты (EEA Finalists).

Средний уровень - «Признанное Совершенство»(“Recognised for Excellence")

Начальный уровень - «Стремление к совершенству» (“Committed to Excellence").

За период с 2001 - 2010 приняли участие и были признаны призерами, финалистами, лаурятами и получили признание в EFQM 21 российский вуз.

3. Модели национальных и региональных премий по качеству и их модификации для высшего образования. В 1996 году к числу стран, имеющих национальные премии по качеству, присоединилась Россия. Прототипом для российской премии послужила европейская модель. Модификацией национальной премии по качеству в области образования является конкурс Министерства образования РФ «Внутривузовские системы обеспечения качества подготовки специалистов», который проводится с 2000г. в России.

В последние годы модель самооценки получила распространение и среди российских вузов. В России высшие образовательные учреждения могут принимать участие в следующих конкурсах на соискание премий в области качества:

1. конкурс на соискание премии Правительства РФ в области качества;

2. региональные конкурсы в области качества (например, премия Санкт-Петербурга в области качества, премии качества Новосибирской, Астраханской, Томской, Кемеровской областей и др.). 
Для участия в конкурсе вуз проводит самооценку и представляет отчет и заявку. Проводится экспертиза отчетов и посещение вузов экспертами.

Следует отметить, что вузы недостаточно активно участвуют в конкурсах на соискание премии Правительства РФ в области качества и региональных конкурсах. Низкая активность объясняется, с одной стороны, неосведомленностью высших учебных заведений о данных конкурсах, a, с другой стороны, слабой готовностью к участию. Кроме того, необходимо отметить и существенный недостаток организации данных конкурсов, предполагающей только две номинации: производство и сфера услуг. Учебные заведения, в том числе и вузы, проходят в номинации «Организации сферы услуг» вместе с предприятиями гостиничного бизнеса, туристическими фирмами и т.д. Соответственно эксперты, проводящие оценку отчетов конкурсантов, недостаточно владеют спецификой деятельности вузов и не всегда могут адекватно оценить достижения вузов в области качества.

Учитывая эти недостатки, Министерство образования РФ сформировало отраслевой конкурс «Внутривузовские системы обеспечения качества подготовки специалистов». Эта модель базируется на основных принципах построения модели премии Правительства РФ в области качества и моделей региональных конкурсов в этой области. Координационную деятельность осуществляет Совет конкурса, утвержденный Минобразованием РФ. Базовым вузом по проведению конкурса назначен Московский государственный институт стали и сплавов (технический университет), первый вуз - лауреат Премии Правительства РФ в области качества.

Для координации внедрения систем менеджмента качества в высших учебных заведениях создан Совет по координации управления качеством профессионального образования РФ, которым в 2007 году в 
рамках Федеральной целевой программы развития образования на 2006 2010 годы проведена доработка нормативно-методического сопровождения внедрения типовой модели системы качества образовательных учреждений (далее - СКОУ), а также апробация методики внешней оценки этой системы, в которой приняли участие учреждения высшего профессионального образования.

Проведена доработка методического обеспечения типовой модели СКОУ для вузов, подготовлены проекты нормативных документов для формирования отраслевой системы аттестации СКОУ профессионального образования: квалификационные требования к экспертам-аудиторам СКОУ; положение о комиссии по аттестации СКОУ; формы документов об аттестации СКОУ и о квалификации эксперта-аудитора СКОУ; проект «Положения по признанию органов по сертификации систем управления ОУ».

Создана система сопровождения внедрения типовой модели СКОУ в высших учебных заведениях, включающая три региональных центра по сопровождению внедрения типовых моделей: в Сибирском Федеральном округе на базе Сибирского государственного технологического университета (СибГТУ), в Уральском Федеральном округе на базе Уральского государственного технического университета - УПИ, в Центральном Федеральном округе на базе Государственного технологического университета «Московского института стали и сплавов» (МИСиС).

В настоящее время типовая модель СКОУ внедрена в девяти вузах: Алтайском государственном техническом университете им. И. И. Ползунова, Архангельском государственном техническом университете, Белгородском государственном университете, Иркутском государственном техническом университете, МИСиС, Московском 
гуманитарном университете, СибГТУ, УПИ, Уральской государственной архитектурно-художественной академии.

В целом же внедрение и функционирование систем управления качеством в вузах вне зависимости от выбранной модели способно повысить качество образовательных услуг, представляемых конкретным вузом, и на этой основе обеспечить качество образовательных услуг.

Библиографический список:

1. Концепция модернизации российского образования на период до 2010 года. - М., 2001.

2. Модернизация системы обучения в СПбГУЭФ. Выпуск 5. Болонский процесс: опыт и перспективы реализации. Методические рекомендации / Бурова Н.В., Горбашко Е.А., Жанказиев А.Х., Клементовичус Я.Я., Максимцев И.А.; Под общ. Ред. Горбашко Е.А.. - СПб.: Изд-во СПбГУЭФ, 2005.

3. Бурденко Е.В. Рынок образовательных услуг в трансформируемой экономике. - М.: РЭА им. Г.В. Плеханова, 2004. с.194. (Диссер-ция на соискание ученой степени канд. экон. наук).

4. Бурденко Е.В. Эволюция взглядов ученых на роль и значение образования в развитии общества и человека//Наука и образование. Новые технологии: Межвузовский сборник научных трудов, вып. №1. Изд. МГУДТ, Москва, 2006. с.3-8.

5. www.efqm-rus.ru 